\title{
Curl Reversion and Damage: The Effect of Different Temperature Treatments on Hair
}

\author{
Abbasi A. Gandhi ${ }^{*}$, Stephanie Kipling, Liam Wright, and Steven G Latham \\ GHD (Jemella Group Ltd.), Cambridge, CB21 6AD, United Kingdom
}

*Corresponding author: Abbasi A.Gandhi, GHD (Jemella Group Ltd.), Cambridge, CB21 6AD, United Kingdom, Tel: +44 (0) 1223 824 346 ; Email: a.gandhi@ghdhair.com

Received date: December 07, 2017; Accepted date: January 10, 2018; Published date: January 15, 2018

Copyright: () 2018 Gandhi AA, et al. This is an open-access article distributed under the terms of the Creative Commons Attribution License, which permits unrestricted use, distribution, and reproduction in any medium, provided the original author and source are credited.

\begin{abstract}
Background and objective: Consumers following the Natural hair movement want to style their hair without thermal damage concerns. When women used a hotter styler, their hair could not revert back to its natural pattern after wetting and they expressed anxiety about heat damage. This study supports these observations using objective measurements of reversion and damage after heat treatment.
\end{abstract}

Methods: Curly tresses were straightened fifty times at $185^{\circ} \mathrm{C}$ or $220^{\circ} \mathrm{C}$. Reversion was compared between treatments and to natural variation after immersion in water. The damage was explored using differential scanning calorimetry and tensile testing.

Results: The treatment at $220^{\circ} \mathrm{C}$ causes a significant shift to less curly types indicating that the fibres were unable to revert back to their original curl pattern. The DSC and tensile results suggest that the cortex structure has been damaged and the fibres have become less stiff and break more easily after the treatment at $220^{\circ} \mathrm{C}$ but not at $185^{\circ} \mathrm{C}$.

Conclusions: The structural damage at $220^{\circ} \mathrm{C}$ suggests that the shape memory effect cannot be triggered adequately by the presence of water and the fibres cannot return to their natural curl state.

\section{Introduction}

In-house surveys have revealed that many consumers desire hair styling tools that provide quicker styling with longer-lasting results and reduced damage compared to their current styling regime. The followers of the Natural hair movements [1] have two main desires: 1) reduction of thermo-mechanical damage and 2) reversion of natural curls after heat styling. Several studies have investigated the physical, structural and thermo-mechanical properties of curly and Afrotextured hair types [2-10].

Our internal study suggested that when consumers are allowed to vary the plate temperature of their styler $73 \%$ increase it above the 'medium' setting and $31 \%$ use the 'high' setting. As manufacturers have responded to pressures of the marketplace, operating temperatures have increased to $\sim 230^{\circ} \mathrm{C}$, which enters the range of keratin denaturation and pyrolysis of dry hair [11-14]. It is generally believed that increasing the plate temperature of a styler results in improved styling performance $[15,16]$. However heat treatments at high temperatures induce extensive damage to morphological components of human hair [17-21]. A recent study investigated the effects on damage indicators when styling with temperatures above $185^{\circ} \mathrm{C}$ [22], close to where the denaturation process of the microfibrils starts [23]. Hair breakage due to thermo-mechanical damage is primary concern for consumers wanting to heat style their hair [24].

Progressive hair straightening using heat [25] has been investigated as has water induced reversion in animal hair [26], but to the authors' knowledge no studies have examined reversion of curly hair after heat treatment. In a small-scale internal study, women with a range of curly hair types tested a styler operating at $185^{\circ} \mathrm{C}$. They reported that their hair reverted to its natural curl pattern successfully after wetting with no signs of damage. When using a hotter styler, they reported loss of reversion.

In this study the degree to which reversion occurs after heat treatment at different temperatures is explored. The degree of internal structural damage was determined using differential scanning calorimetry (DSC) and tensile testing.

\section{Materials and Methods}

\section{Reversion}

Curly hair (Afro-textured) from six individual heads was purchased from International Hair Importers \& Products (each tress: $\sim 2 \mathrm{gm}$ weight). Stylers with a plate temperature of $185^{\circ} \mathrm{C}$ and $220^{\circ} \mathrm{C}$ were used. Two tresses from each head were used per treatment.

The tresses were subjected to an initial wash and dried overnight in a constant $23^{\circ} \mathrm{C}$ and $50 \% \mathrm{RH}$ environment. 30 fibres from four places on each tress were selected. The fibres were extended, and a $6 \mathrm{~cm}$ length cut from each fibre. These were placed in deionised water for five minutes then removed and returned to the constant environment overnight to dry and revert to as close to their natural curl pattern as possible. The curl type of each fibre was identified using the L'Oréal method $[27,28]$. This method yields a scale of eight curl types; Type I, lowest through to Type VIII, highest, level of curl. 
The tresses were then treated 50 times at either $185^{\circ} \mathrm{C}$ or $220^{\circ} \mathrm{C}$ using an automated rig to ensure the force between the plates was $4 \pm$ $1 \mathrm{~N}$ and the pull rate was $20 \mathrm{~mm} / \mathrm{s}$. The tresses were rotated by $90^{\circ}$ between passes. After treatment another 30 fibres were removed from each tress and the reversion and classification processes were repeated.

\section{Damage}

For both DSC and tensile testing $2.1 \mathrm{~g}$, dark curly tresses $175 \mathrm{~mm}$ long were purchased from Hugo Royer International Ltd (Sandhurst, Berkshire, UK). The tresses underwent a wash before testing commenced and were heat treated as previously described. Two tresses were used per temperature.

A Perkin Elmer DSC-6000 system (Perkin Elmer, Seer Green, Buckinghamshire, UK) was used for denaturation temperature and enthalpy measurement [14]. The fibres were chopped into small $(<2$ $\mathrm{mm})$ sections and $6 \pm 1 \mathrm{mg}$ of snippets was placed in a sealed aluminium sample pan with $50 \mu \mathrm{l}$ deionised water. Samples were heated at a rate of $10^{\circ} \mathrm{C} / \mathrm{min}$ between $30^{\circ} \mathrm{C}-200^{\circ} \mathrm{C}$. Two samples were prepared per tress.

For tensile testing 50 fibres were selected from each tress. Fibre diameters were measured using a Dia-Stron FDAS 770 fibre dimensional analysis system (Dia-Stron Ltd., Andover, Hampshire, UK). The tensile apparatus, a Dia-Stron MTT175, applied a stress to the fibres until breakage under controlled conditions of $23^{\circ} \mathrm{C}$ and $50 \%$ $\mathrm{RH}$. Elastic modulus and break stress for each treatment were averaged over the values obtained from both tresses.

\section{Results and Discussion}

The number of fibres of each curl type was counted before and after heat treatment to gauge the effect of the heat treatment. Before heat treatment the fibres were Types V, VI and VII.

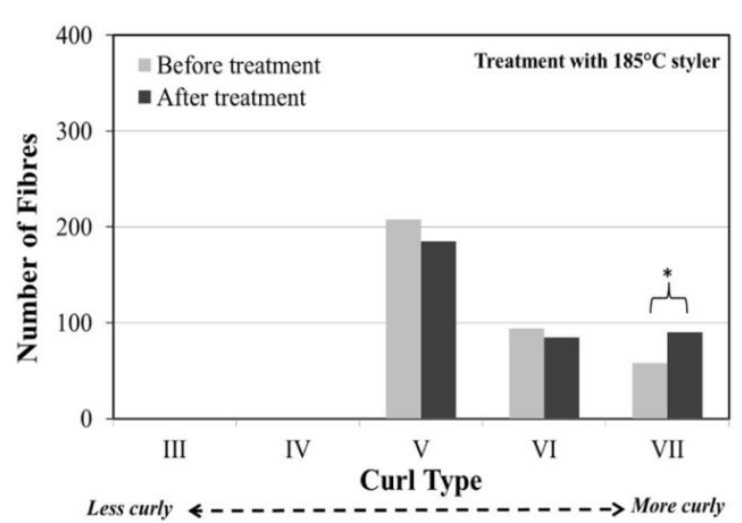

Figure 1: Curl type before and after heat treatment with a $185^{\circ} \mathrm{C}$ styler. The asterisk indicates a statistically significant difference $(\mathrm{p}<0.05)$.

The graph in (Figure 1) shows the number of fibres of each type before and after 50 passes using a styler with a plate temperature of $185^{\circ} \mathrm{C}$. There is no statistically significant change in Type V and Type VI fibres; however, there is a small increase in Type VII fibres. This may have arisen due to bias in the fibre selection process. True randomness with no bias would require as many place choices as there are fibres in the tress which is impractical. In this experiment, the bias is reduced by choosing each group of fibres from four places on the tress instead of one.

The effect of using a styler with a plate temperature of $220^{\circ} \mathrm{C}$ can be seen in the graph in (Figure 2). The heat treatment causes statistically significant decreases in Type VI and VII fibres and a statistically significant increase in Type V and IV fibres. There is a shift towards Type V and lower curl types, with some Type III and IV fibres observed. This shift to less curly types indicates that the fibres were unable to revert back to their original curl pattern.

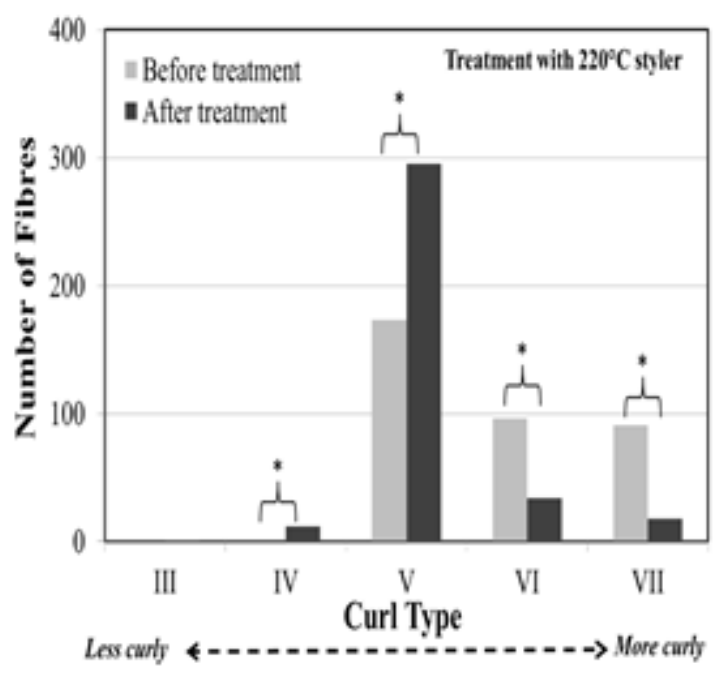

Figure 2: Curl type before and after heat treatment with a $220^{\circ} \mathrm{C}$ styler. The asterisk indicates a statistically significant difference $(\mathrm{p}<0.05)$.

There is variation in the tresses used in this study. This is shown as the shaded region in the graph in (Figure 3). The natural variation was calculated as the proportional difference between the fibres of tresses from the same head before treatment. This was then averaged across all heads.

The percentage of fibres that changed after heat treatment is shown in (Figure 3). The increase in curliness of $9.2 \pm 4.1 \%$ when using a styler at $185^{\circ} \mathrm{C}$ is smaller than the natural variation of the hair at $17.0 \pm$ $2.8 \%$. The natural variation means that if one was to select two random samples from the tress, an apparent increase or decrease of up to $20 \%$ could be observed without carrying out any heat treatment. Hence any change in curl type below $20 \%$ is indistinguishable from natural variation. Due to the inability of the fibres treated at $220^{\circ} \mathrm{C}$ to revert to their natural curl pattern, $37.5 \pm 4.4 \%$ of fibres changed towards less curly types. This change is larger than the natural variation, and so can be attributed to the heat treatment.

In addition to investigating at the level of individual fibres, the ability of a tress to return to its natural curl pattern was determined. All of the tresses straightened at $185^{\circ} \mathrm{C}$ displayed no statistically significant difference after heat treatment. However, only $25 \%$ of the tresses straightened at $220^{\circ} \mathrm{C}$ showed no statistically significant difference. This supports the fibre results as most tresses heat treated at $220^{\circ} \mathrm{C}$ were unable to revert successfully. 


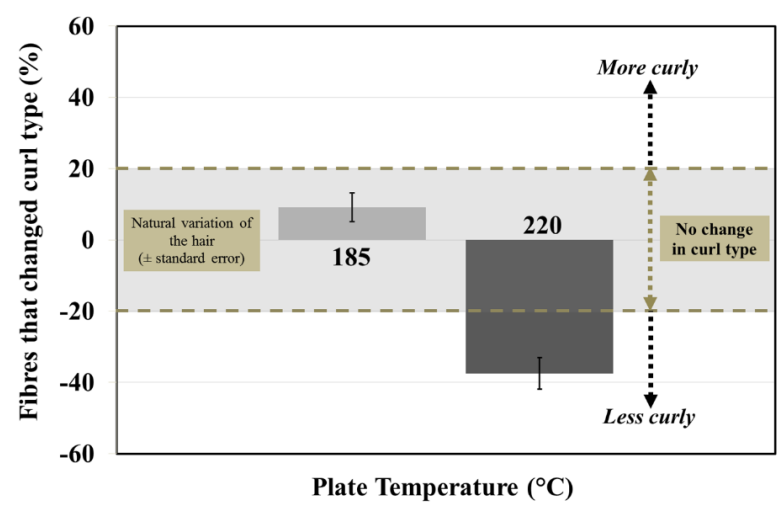

Figure 3: Comparing shift in curl type due to heat treatment with natural variation of hair. Error bars represent standard error.

(Figures 4 and 5) show denaturation temperature and enthalpy respectively for both before and after the two heat treatments. A previous study concluded that the endothermic effect occurs due to events within the cortex [29]. The denaturation temperature is associated with viscosity of the IFAP (intermediate filament associated proteins, the matrix phase) $[13,30]$. Whereas the denaturation enthalpy is related to denaturing of IF (intermediate filaments, the crystalline phase) and breaking of the IFAP-IF interface [29,31,32]. If the thermal treatment causes internal damage, the denaturation temperature/ enthalpy after treatment will be statistically significantly lower than that before treatment. The results in Figure 4 show that the denaturation temperature for the treatment with the $220^{\circ} \mathrm{C}$ styler, $146.3 \pm 0.9^{\circ} \mathrm{C}$ is significantly lower than the control at $157.9 \pm 0.5^{\circ} \mathrm{C}$. However, the treatment at $185^{\circ} \mathrm{C}$ produced no significant difference to the control. The same is true for the denaturation enthalpy. The treatment at $220^{\circ} \mathrm{C}$ gives a corresponding value of $4.77 \pm 0.03 \mathrm{~J} / \mathrm{g}$ and is significantly smaller than the value of the control $(12.68 \pm 0.36 \mathrm{~J} / \mathrm{g})$. For the $185^{\circ} \mathrm{C}$ heat treatment there is no significant difference between control and treatment. The DSC results shown in Figures 4 and 5 suggest that the internal structure of the hair has been damaged during the treatment at $220^{\circ} \mathrm{C}$ but not when treated at $185^{\circ} \mathrm{C}$. Further, the treatment at $220^{\circ} \mathrm{C}$ induces three alterations: 1) changes the matrix (IFAP) viscosity leading to more freedom of movement, 2) breaks IFAP-IF interface bonds, likely to be disulphide bonds and 3) breaks $\alpha$ keratin backbone/branches leading to disintegration of the IF structure. The proposed structural model for the water-sensitive shape memory mechanism of animal hair [26] suggests that internal structural alterations would hinder the recovery of the fibre's innate shape after wetting and drying. These three alterations explain our reversion results on fibres treated at $220^{\circ} \mathrm{C}$. The tensile parameters of break stress and elastic modulus are shown in (Figures 6 and 7). There is a significant decrease in break stress and elastic modulus compared to the control tresses for the fibres treated at $220^{\circ} \mathrm{C}$. However there is no statistically significant decrease in either parameter for fibres treated at $185^{\circ} \mathrm{C}$. The results on break stress and elastic modulus infer damage from the $220^{\circ} \mathrm{C}$ but not from the $185^{\circ} \mathrm{C}$ treatment. The change in elastic modulus shows that the highest temperature treatment has produced fibres that are less stiff and break more easily. The DSC results suggest this is caused by loss of integrity of the molecular structure such that there are fewer bonds in the molecular framework. In terms of the water-sensitive shape memory model this loss of structure means that the shape memory effect cannot be activated to the same extent by the presence of water and therefore the fibre cannot return to its former shape.

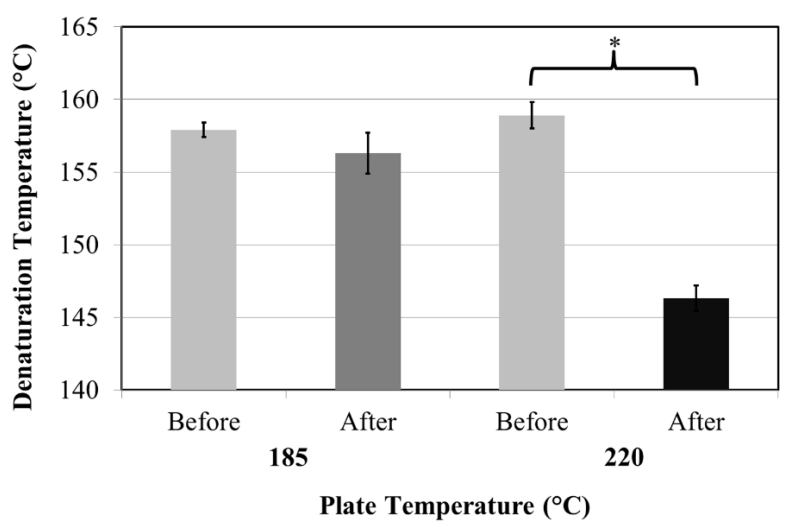

Figure 4: The denaturation temperature before and after heat treatments. The asterisk indicates a statistically significant difference $(\mathrm{p}<0.05)$. Error bars represent standard error.

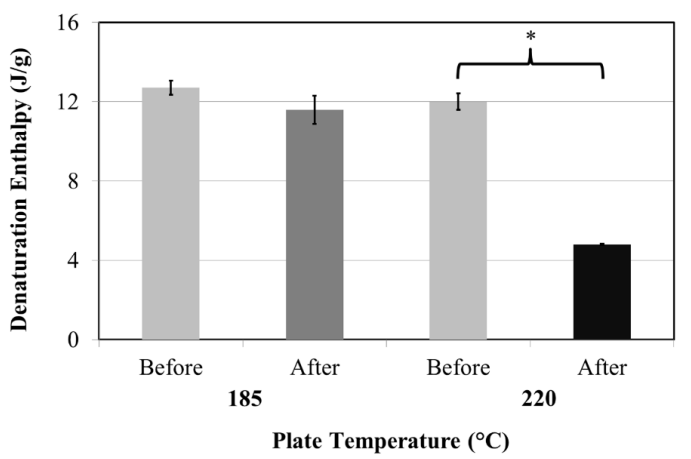

Figure 5: The denaturation enthalpy before and after heat treatments. The asterisk indicates a statistically significant difference $(\mathrm{p}<0.05)$. Error bars represent standard error.

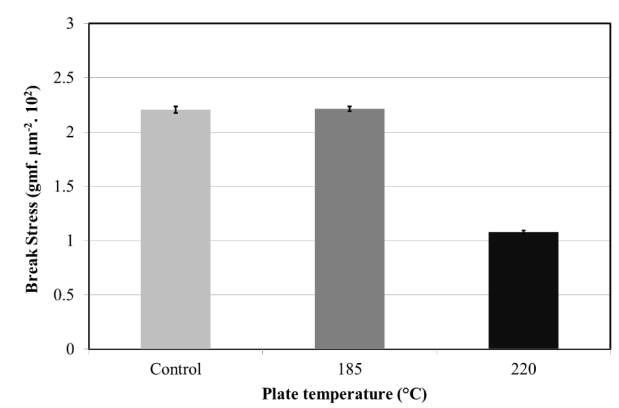

Figure 6: Comparing elastic modulus after heat treatment with control (before heat treatment). Error bars represent standard error. 


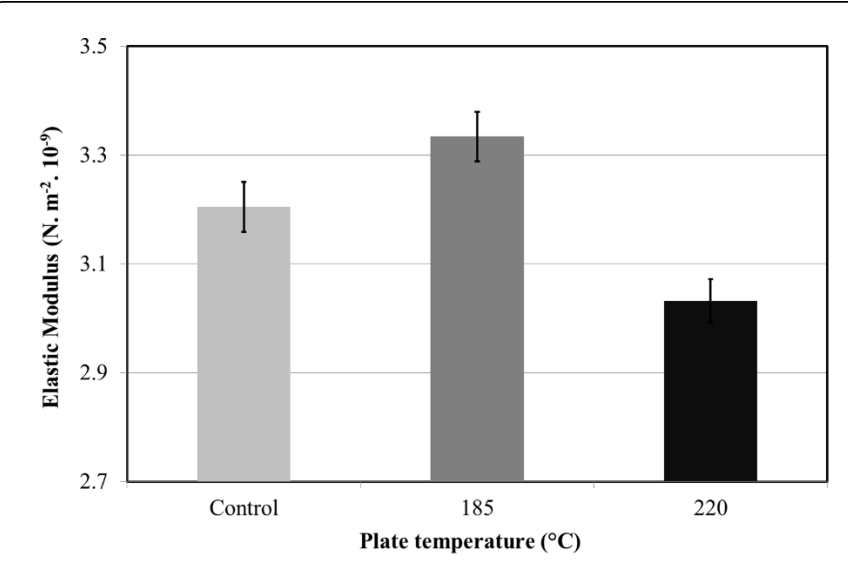

Figure 7: Comparing break stress after heat treatment with control (before heat treatment). Error bars represent standard error.

\section{Conclusion}

The data reported here shows that after straightening curly hair tresses using a styler at $185^{\circ} \mathrm{C}$, the hair's ability to revert to its natural curl pattern is unaffected. However, when using a styler at $220^{\circ} \mathrm{C}$ the hair tresses show a reduction in reversion and shift to lower curl types. It is suggested that the structural damage, lower stiffness and tendency to break at lower stress levels induced in hair treated at $220^{\circ} \mathrm{C}$, inferred by a reduction in denaturation parameters and a change in elastic modulus and break stress, is the cause of the inability of the fibres to revert successfully. There is no change in the denaturation parameters or in the elastic modulus and break stress after treatment at $185^{\circ} \mathrm{C}$ and hence the fibres revert sucessfully.

\section{References}

1. Hahn J, Dandridge T, Seshadri P, Marconnet A, Reid T (2015) Integrating designmethodology, thermal sciences and customer needs to address challenges in the hair care industry. ASME Proceedings 7: 46551-46561.

2. Bryant H, Porter C, Yang G (2012) Curly hair: measured differences and contribution to breakage. Int J Dermatol 51: 8-11.

3. Porter CE, Dixon F, Khine CC, Pistorio B, Bryant H, et al. (2009) The behaviour of hair from different countries. J Cosmet Sci 60: 97-109.

4. Syed AN, Kuhajda A, Ayoub H, Ahmed K (1995) African-American hairits physical properties and differences relative to Caucasian hair. Cosmet \& Toiletries Mag 110: 39-48.

5. Kamath YK, Hornby S, Weigmann HD (1984) Mechanical and fractographic behavior of Negroid hair. J Soc Cosmet Chem 35: 21-43.

6. Menkart J, Wolfram LJ, Mao I (1966) Caucassian hair, Negro hair, and wool: similarities and differences. J Soc Cosmet Chem 17: 769-787.

7. Porter CE, Diridollou S, Barbosa VH (2005) The influence of AfricanAmerican hair's curl pattern on its mechanical properties. Int J Dermatol 44: 4-5.

8. Epps JA, Wolfram LJ (1983) Combing differences between Caucasian and Black hair. J Soc Cosmet Chem 34: 213-214.
9. Mc Michael AJ (2007) Hair breakage in normal and weathered hair: focus on the Black patient. J Investig Dermatol Symp Proc 12: 6-9.

10. Wolfram LJ (2003) Humain hair: a unique physicochemical composite. J Am Acad Dermatol 48: 106-114.

11. Spei M, Holzem R (1989) Thermoanalytical determination of the relative helix content of keratins. Colloid \& polym Sci 267: 549-551.

12. Monteiro VF, Maciel AP, Longo E (2005) Thermal analysis of Caucasian human hair. J Therm Anal Calorim 79: 289-293.

13. Christian P, Winsey N, Whatmough M, Cornwell PA (2011) The effects of water on hair-styling damage. J Cosmet Sci 62: 15-27.

14. Wortmann FJ, Wortmann G, Marsh J, Meinert K (2012) Thermal denaturation and structural changes of $\alpha$-helical proteins in keratins. J Struct Biol 177: 553-560.

15. Harper D, Qi JC, Kaplan P (2011) Thermal styling: Efficacy, convenience, damage tradeoffs. J Cosmet Sci 62: 139-147.

16. Evans TA (2015) Beating the Damaging Effects of Heat on Hair. Cosmet \& Toiletries 130: 28-33.

17. Gamez-Garcia M (1998) The cracking of human hair cuticles by cyclical thermal stresses. J Cosmet Sci 49: 141-153.

18. Lee YL, Kim YD, Hyun HJ, Pi LQ, Jin X, et al. (2011) Hair shaft damage from heat and drying time of hair dryer. Ann Dermatol 23: 455-462.

19. McMullen R, Jachowicz J (1998) Thermal degradation of hair. I. effect of curling irons. J Cosmet Sci 49: 223-244.

20. Nogueira AC, Scanavez C, Carnelo C, Gaspari A, Joeken I (2004) Hair color changes caused by dyeing and thermal treatments. J Cosmet Sci 55: 437-447.

21. Gamez-Garcia M (2011) Void and pore formation inside the hair cortex by a denaturation and super-contraction process occurring during hair setting with hot irons. J Cosmet Sci 62: 109-210.

22. Wright LH, Brown CS, Cockcroft S, Gandhi AA, Diaz AF, et al. (2015) Identifying the optimum temperature range for using a styler on human hair. 19th International Hair Science Symposium, Trier, Germany.

23. Marzec E (1998) The influence of hydration and ionizing radiation on denaturation process in keratin. Bioelectroch Bioener 46: 279-284.

24. Davis SA (2001) The science of black hair: A comprehensive guide to textured hair care. Saja Publishing Company, Texas, USA.

25. Dussaud A, Rana B, Lam HT (2013) Progressive hair straightening using an automated flat iron: function of silicones. J Cosmet Sci 64: 119-131.

26. Xiao X, Jinlian H (2016) Animal hairs as water-stimulated shape memory materials: mechanism and structural networks in molecular assemblies. Sci Rep 6: 26393.

27. de la Mettrie R, Saint-Léger D, Loussouarn G, Garcel A, Porter C, et al. (2007) Shape variability and classification of human hair: a worldwide approach. Hum Biol 79: 265-281.

28. Loussouarn G, Garcel AL, Lozano I, Collaudin C, Porter C, et al. (2007) Worldwide diversity of hair curliness: a new method of assessment. Int J Dermatol 46: 2-6.

29. Popescu C, Gummer C (2016) DSC of human hair: a tool for claim support or incorrect data analysis?. Int J Cosmet Sci 38: 433-439.

30. Wortmann FJ, Deutz H (1993) Characterizing keratins using highpressure differential scanning calorimetry (HPDSC). J App Pol Sci 48: 137-150.

31. Istrate D, Popescu C, Rafik ME, Möller M (2013) The effect of pH on the thermal stability of fibrous hard alpha-keratins. Polym Degrad Stab 98: 542-549.

32. Istrate D, Popescu C, Möller M (2009) The effect of $\mathrm{pH}$ on the thermal stability of fibrous hard alpha-keratins. Macromol Biosci 9: 805-812. 